ORIGINAL PROF-2175

\title{
ARTHRITIS IMPAIRMENT;
}

Need assessment, designing and effectiveness of adaptive clothing for females

Mrs. Naheed Azher, Dr. Samia Kalsoom, Muhammad Saeed

ABSTRACT... Objective: The purpose of this study was to explore physical limitations and clothing problems among women with Rheumatoid arthritis and designing functional clothing according to their needs. Design: This study is designed to be qualitative in nature, where the researcher explores case studies of adult female with rheumatoid arthritis. Therefore qualitative methods were used, employing data collection by in-depth interviews and observations. Period: The study was conducted in 2010- 2012 in Lahore. Material \& Methods: The present study gives a clear picture about clothing problems while donning and doffing, of adult females with rheumatoid arthritis and the need for adaptive clothing. Research process comprised of assessing clothing needs, providing comfort while donning and doffing through co-designing and evaluating comfort of an adaptive garment after wear trail of three weeks. The researcher did a detailed thematic analysis using predetermined codes to aid analysis, of all the information gathered from three female participants of the study. The researcher found what was missing in the clothing that the participants wore in their regular lives, and worked with them to find out what they wanted in the adaptive clothing that provides them comfort. Results: The adaptive clothing was a successful mean to satisfy the participant's needs and preferences in a better way. It was also found that the co-designing of the final product was a very effective means of doing so; adaptive clothing can offer arthritis women an easy, time saving and pain free way to dress.

Key words: Rheumatoid arthritis, adaptive clothing, clothing comfort, physical limitations, donning and doffing.

Article Citation

Azhar N, Kalsoom S, Saeed M. Arthritis impairment; need assessment, designing and effectiveness of adaptive clothing for females. Professional Med J 2013;20(6): 938-947.

\section{INTRODUCTION}

Clothing governs the impression a person will be able to make on others and give them a sense of security, through feelings of acceptance and through selfesteem ${ }^{1}$. Clothing helps to build and enrich the personality of the wearer, being the main source of forming first impression for others. If the first impression is poor it may create avoidance, where as if the first reaction is favorable, a pleasant interaction between the individuals usually ensures ${ }^{2}$. The appearance that is enhanced by the clothes an individual wears makes them feel more confident and comfortable through acceptance, and also shows their personality by the way they dress themselves ${ }^{3,4}$.

Clothes gives a feeling of self-confidence and comfort and the wearer feels physically, psychologically and socially at ease. Uncomfortable clothes can take away the joy of living ${ }^{5-7}$. This is equally true for special groups, whose needs are of greater care because they need more comfort and convenience as compared to normal people to become independent. Special group consists of people who deviate from the normal with respect to physical, mental and social characteristics to such an extent that they need exclusive care in clothing $^{2}$. The present study is aimed to catalogue the clothing problems faced by the females with Rheumatoid arthritis and to study the preference according to their physical limitation.

Rheumatoid arthritis is a chronic, progressive and disabling auto-immune disease. In rheumatoid arthritis the individual faces problems in multiple joints of the body, causing swelling, sever pain and destruction of the joint as well as facing deformity. This type of a disease typically affects the small finger joints, wrists, knees and toes. All joints of the body however are potential targets. Thus rheumatoid arthritis can be one of the most disabling types of arthritis. It is also more common disease now a day ${ }^{8-10}$.

Adaptive clothing is a special clothing design made for people with impairment, who face difficulties in dressing themselves. These specially designed 
clothes make clothing experience easy, and cater a wide range of disabilities. Each disability requires a different type of design according to their disabilities ${ }^{11}$. Adaptive clothing helps to minimize joint movements and pain faced by patient while dressing or undressing. It also decreases the amount of patient handling performed by attendant ${ }^{12}$. Thus adaptive clothing allows making life easier for special people, and the correct adaptive clothing design gives an opportunity to enjoy life and becomes a wonderful way to prove that sick people with special needs and disabilities may improve the quality of their life ${ }^{13,14}$.

Some disabled people are not able to change in and out of clothing that is not designed for their disability, and so they have to adapt to them ${ }^{15}$. This study was aimed at identifying the clothing problems faced by the females with Rheumatoid arthritis and to investigate their preferences according to their physical limitation, and design suitable clothing in this regard. It addresses the two key questions:

1. Which areas of dress require adaptations for adult females of Pakistan suffering from Rheumatoid arthritis?

2. How adaptive clothing increases the comfort of adult females with Rheumatoid arthritis?

\section{METHODS AND MATERIALS}

The study was conducted in 2010- 2012 in three hospitals of Lahore. The purpose of this study was to design suitable clothing for adult females of Pakistan suffering from Rheumatoid arthritis. The study was exploratory in nature; therefore qualitative methods were used to achieve the objectives of the research. The researcher explores case studies on adaptive clothing for three adult female patients with rheumatoid arthritis impairment in Pakistan. Understanding and deeply exploring the possibilities of making suitable clothing for females with Rheumatoid arthritis.

The sample of the study was purposively drawn.
According to Gay "qualitative studies can be carried out with a single participant or more depending on researcher's time, money, participant's availability and participant's interests" ${ }^{16}$. So that due to limited resources and time, only three females suffering from rheumatoid arthritis with limited shoulder, hand and wrist, finger and knee movement were taken as a sample.(See table ) Patients were selected by the recommendation of orthopedic specialist. Three hospitals and rehabilitation center, namely, Rheumatology Department of Sheikh Zayed hospital, Orthopedic Department of Fatima Memorial hospital, and Rehabilitation Centre on Ferozpur Road, (all these are situated in Lahore) were visited by the researcher, (after getting formal permission from them), this was mainly done to get first-hand knowledge and information, and to collect a sound sample for the study.

\begin{tabular}{|c|c|l|}
\hline $\begin{array}{c}\text { Participant } \\
\text { code }\end{array}$ & Age & \multicolumn{1}{|c|}{ Physical Disabilities } \\
\hline 01 & 42 & $\begin{array}{l}\text { Limited shoulder, both wrists, finger } \\
\text { and knee movement }\end{array}$ \\
\hline 02 & 38 & $\begin{array}{l}\text { Rhematoid arthritis effects finger } \\
\text { joints, elbow, Knees and have Frozen } \\
\text { shoulder }\end{array}$ \\
\hline 03 & 55 & $\begin{array}{l}\text { Rhematoid arthritis effects all small } \\
\text { and large joints of the body (on } \\
\text { wheelchair) }\end{array}$ \\
\hline \multicolumn{2}{|c|}{ Table-I. Description of study participants and their } \\
physical disabilities
\end{tabular}

Qualitative research design with inductive approach was used for data collection. Therefore in-depth interviews and observations were used for data collection of the study ${ }^{17}$. The researcher used common methods like interviewing the medical specialist to develop an understanding of rheumatoid arthritis. In addition to that, in depth interviews and observations with patients help to illuminate basic elements of alterations required in their garments and to understand the context of the limitations that they face. 
The interviews and observations were based upon the aspects of comfort in relation to clothing. The patients expressed their needs, and these needs were made the basic criterion for the design of the adaptive clothing for them.

Interviews are considered a direct method for data collection ${ }^{18}$. In order to gather comprehensive data, a series of interviews was conducted. In order to maintain a level of confidence, the researcher remains conscious and careful to gain trust of the participants. This required a great deal of sensitivity, love and compassion, and they needed to be treated like equal in the society. During the interview, questions about their daily lives, and the problems that they faced were asked. In the beginning research found negative responses towards specially designed clothing, mainly due to the patients' need to hide their feelings and most did not believe that they had a clothing problem. Gradually, as trust level began to increase, than they were open up and start talking about their physical problems.

Another method used was observation, which is an indirect method of data collection in qualitative research ${ }^{18}$. The sample was sensitive and reserved, after various meetings with the patients and the specialists, and gaining trust from the patients, the researcher was then allowed to visit their homes, which gave access to more observational data. This was done by expressing the need to build rapport and better understanding of the physical limitations.

The observations were focusing behavior of the patients, mainly looking at how they walked, sat, ate and how well they were able to grasp things. This allowed proper analysis and observation on their physical limitations. At the same time, attention was given to the types of clothes that were worn by the patients. Through this any objection on other types of clothes were also noted. Each observation of individual patients was all noted separately in order to make sure that the patients' clothing was designed accordingly.

In order to have comprehensive data, an interview protocol was prepared with the help of doctors who screened the contents of the question. Then interview questions were developed in consultation with the research advisor and experts (dress designer).

The researcher used different methods of instrumentation and content analysis, based on a categorization scheme to code and interpret the data ${ }^{19}$. Before content analysis, each audio file of interview dialogue was transcribed into English by the researcher to ensure consistency and validity. All the details of discussion were carefully reviewed and coded for correspondence to the identified categories, which would be meaningful to the research problems. The process of coding data involved seeking recurring themes in the data representing outlines in different categories and themes.

This study was divided into three phases, which followed a linear progression of data collection and analysis. The first phase was focused entirely on gathering data for the need assessment of the specific group of women with rheumatoid arthritis who required the need for adaptive clothing. In this section, all information that was gathered by the researcher through in-depth interviews and observations has been discussed. Individual and aggregate data was presented here, which relate to the information that was gathered by the researcher from all of the three participants. The information includes type of physical limitation, clothing needs and preferences and the body measurements. (See table II)

The second phase is the designing phase, which covered information on collaborating with the participants of the study to design the adaptive garments that bring change in comfort level in participants of the study. This phase also used the 


\begin{tabular}{|c|c|c|c|c|c|c|}
\hline \multicolumn{5}{|c|}{ Clothing dimensions } & \multicolumn{2}{|c|}{ Comments } \\
\hline \multicolumn{5}{|c|}{ Difficulty in donning and doffing } & & \\
\hline \multicolumn{5}{|c|}{ Difficulty managing fasteners } & & \\
\hline \multicolumn{5}{|c|}{ Lack of freedom of movement } & & \\
\hline \multicolumn{5}{|c|}{ Inappropriate and uncomfortable fabric } & & \\
\hline \multicolumn{5}{|c|}{ Inadequate covering of body } & & \\
\hline \multicolumn{5}{|c|}{ Style can be constricting and uncomfortable } & & \\
\hline \multicolumn{5}{|c|}{$\begin{array}{l}\text { Construction quality inadequate exertion of } \\
\text { stress }\end{array}$} & & \\
\hline \multicolumn{5}{|c|}{ Some features are irritating } & & \\
\hline \multicolumn{5}{|c|}{ Not all clothing is aesthetically pleasing } & & \\
\hline \multicolumn{7}{|c|}{ Body measurements } \\
\hline \multirow[t]{2}{*}{ Participants } & \multicolumn{2}{|c|}{ Bust } & \multicolumn{2}{|c|}{ Waist } & \multicolumn{2}{|c|}{ Hip } \\
\hline & Inches & $\mathrm{Cm}$ & Inch. & $\mathrm{Cm}$ & Inch. & $\mathrm{Cm}$ \\
\hline 01 & & & & & & \\
\hline 02 & & & & & & \\
\hline 03 & & & & & & \\
\hline Table- & Potent & toasur & ments & & body & \\
\hline
\end{tabular}

information obtained from Phase I to sketch a design of the garment that would be comfortable and suit the individual needs of the participants. The collaboration involved interactive sessions with the members of the sample to comment on the sketches made in the initial stage of the design, and then finalized the sketch design according to their preferences. With the understanding of what was problematic for the participants and what the participants wanted to see in their clothing, the researcher put together three variations of adaptive clothing design for shirt (kameez) and pants (shalwar) in drawing for each participant. This was then shortlisted by the participants for the construction of the one design for wear trial, so that they could test the clothing.

The third and final phase focused on making a trial garment and given to the participants for wear testing to assess the level of comfort. One out of the three sketches for adaptive clothing designs of phase two made for each participant of the study was selected and constructed for the wear test. The selected design was developed for construction with the help of a detailed specification sheet that contained final body measurements for each participant along with the detailed line sketch of design and its accessories. This specification sheet facilitated the construction process further because it contained detailed information.(See table III)

\begin{tabular}{|c|c|c|c|c|c|c|c|c|}
\hline \multirow{2}{*}{ Participants } & \multicolumn{3}{|c|}{ Bust } & \multicolumn{2}{c|}{ Waist } & \multicolumn{3}{c|}{ Hip } \\
\cline { 2 - 9 } & Inches & $\mathrm{Cm}$ & Inches & $\mathrm{Cm}$ & Inches & $\mathrm{Cm}$ & Inches & $\mathrm{Cm}$ \\
\hline 01 & 36.50 & 90.50 & 31.00 & 79.00 & 39.00 & 99.00 & 42 & 107 \\
\hline 02 & 40.00 & 99.00 & 33.00 & 84.00 & 44.00 & 112.00 & 44 & 112 \\
\hline 03 & 41.50 & 105.00 & 32.00 & 97.00 & 45.00 & 114.00 & 43 & 110 \\
\hline
\end{tabular}


Three sets of this trial adaptive garment were made in accordance with the body measurements of the participants and with the help of a basic pattern for a shalwar and shirt. Wear-test of the trail adaptive garment given by the same group of participants was selected from the start of the research. Phase Three of the research was related to the testing of the adaptive design and to evaluate its effectiveness in relation to comfort, through in-depth interviews and observations. The researcher worked very closely with the participants of the study to design and select one of the three designs made for each participant according to their need and preferences. So three selected adaptive design of shirts were constructed in same colour with same print for each participant. One design of a suggested adaptive shalwar was also chosen for construction for all participants. (See figure 1, 2,3\& 4)

\section{RESULTS AND DISCUSSION}

The findings of the present study are discussed here. Specific physical limitations were common in all the three participants. They were categorized as range of motion, strength, stamina, motor planning, and others. These categories impacted the comfort of this special group while donning and doffing, managing fasteners and also through the style of the clothing ${ }^{20}$. The researcher found the clinical definition of Rheumatoid arthritis to be consistent with the identification of the limitations that were earlier categorized, which was supported by ${ }^{21-23}$. Limitations caused by disease usually impact the ability to find suitable clothing ${ }^{24}$. Through observations and indepth interviews the researcher found significant problem areas that participants were facing in finding clothes that did not constricting them and would give them the freedom to move and the ease to manage fastenings. The problems with constructing style were solved with designing clothes that had full front open shirt with simple set-in-sleeves, Reglan and Kimono sleeves with moderate neck depth and fairly loose garments. Cotton garments are most suitable compared to woolen, silk and synthetics. Velcro fasteners are highly preferred for quick and fast manipulation.

The researcher uses a co-designing technique to find the change in comfort level of the participants, through creating common clothing features according to the need and preferences of participants in the trail adaptive clothing solution. These features included loose clothing with no define waistline. The adaptive clothing also included a front or side opening, with a simple and basic neckline, and a simple collar. A fastening that was used is Velcro. Shalwar with elasticized waist and elastic band at the bottom of each paincha, zippers on shalwarpaincha and on back of the shirts. All participants found all features very comfortable, they open up that zipper with front open shirt and on shalwarpaincha are very helpful for massage. All these features were seen to also be applicable to those who belonged to other groups with similar range of physical disabilities.

The analysis of all the information gathered through qualitative methods and also used predetermined codes to aid analysis of all the information. These codes, that were in form of instrument, allowed the researcher to understand and combine all the responses that came from the participants. The researchers found what was missing in the clothing that the participants wore in their regular lives, and worked with them to find out what they wanted in the adaptive clothing that provides them comfort. Finally, it was found that the adaptive clothing was a successful mean to satisfy the participant's needs and preferences in a better way, as they felt pleased with most of the dimensions of the final part of the research. It was also found that it is important for adaptive clothing to understand what is required and that the co-designing the final product was a very effective means of doing so, as it reduced the amount of problems in the final construction stage. 


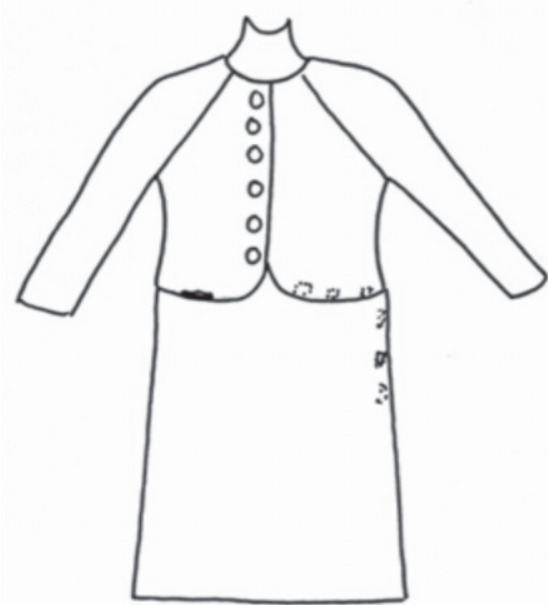

Adapted Pattern Front

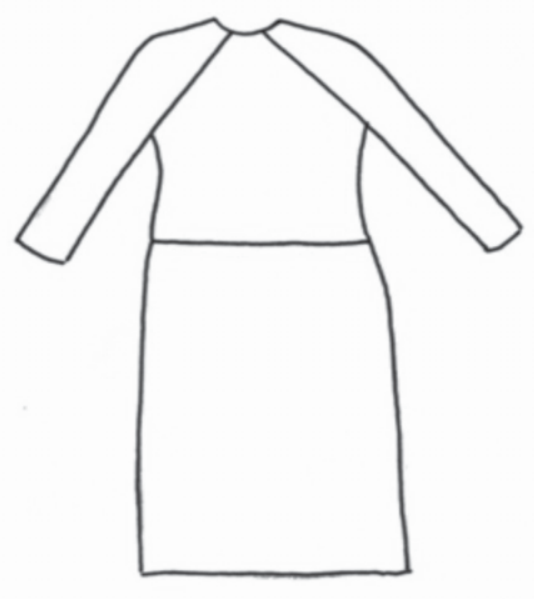

Adapted Pattern Back

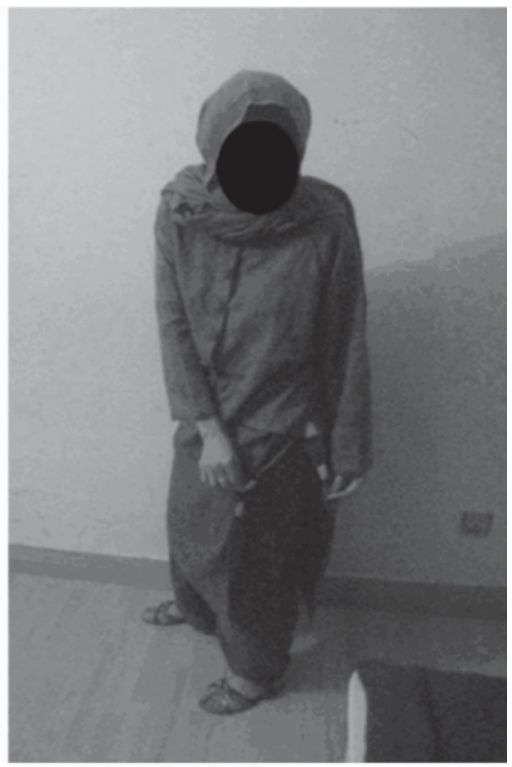

Fig-1. Description of trail adaptive design

A one piece plain with printed bodies and loose fitted shirt with full center and side opening, with decorative large button having Velcro underneath. Half back zip, Raglan sleeve with plain piping, and a pocket.

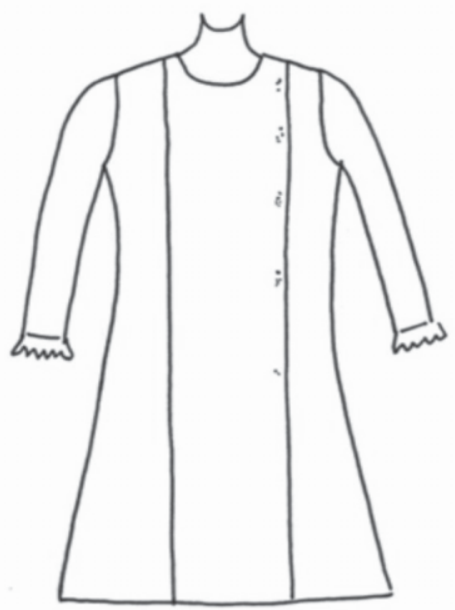

Adapted Pattern Front

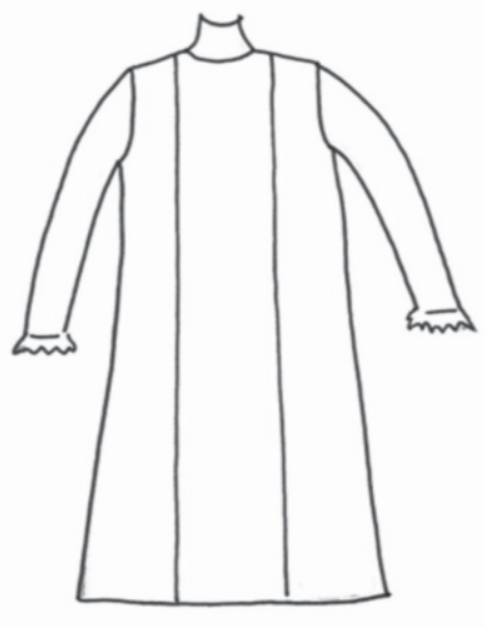

Adapted Pattern Back

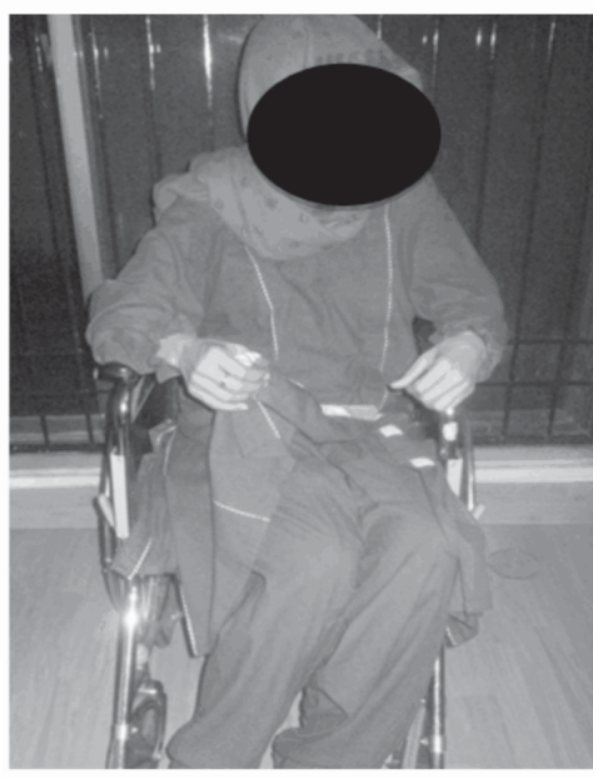

Fig-2. Description of trail adaptive design

A full one side front opening with cancelled Velcro and decorative piping on both sides.

Plain set-in-sleeve with loose elasticize wrist opening, and half back zip. 


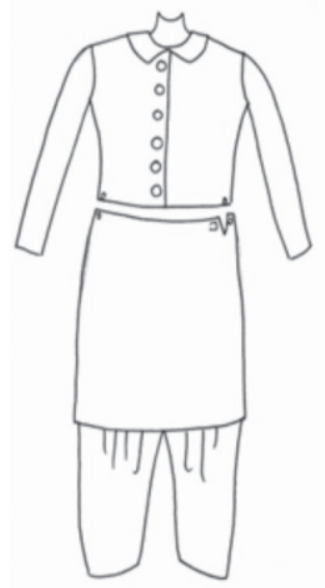

Adapted Pattern Front

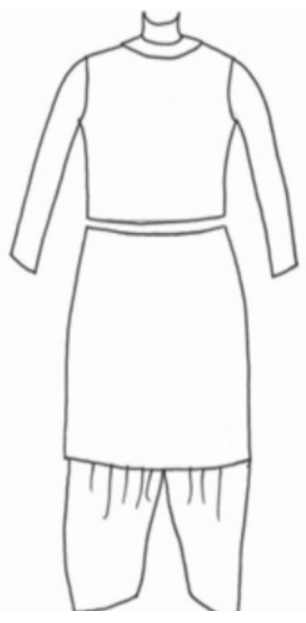

Adapted Pattern Back
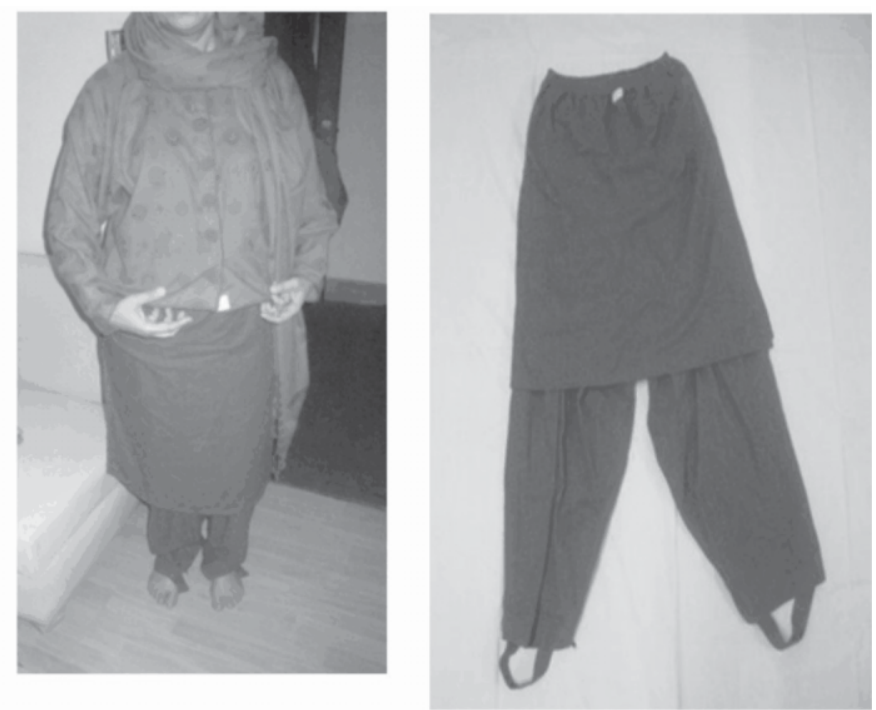

Fig-3. Description of trail adaptive design

A loose fitted full center front open printed blouse with collar and decorative large buttons with concealed Velcro, and Kimono sleeve. Lower part of the shirt is attached with shalwar.

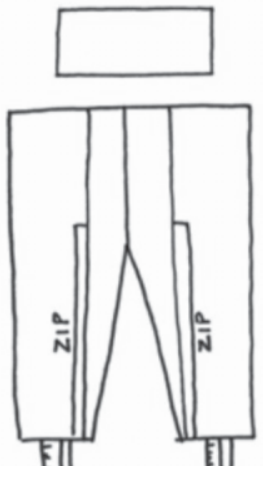

Adapted Pattern Front

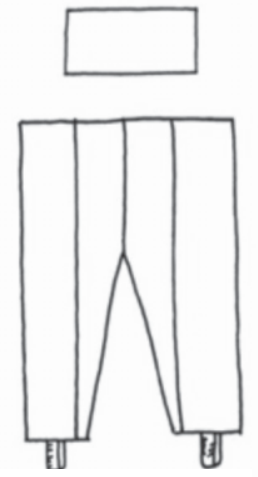

Adapted Pattern Back

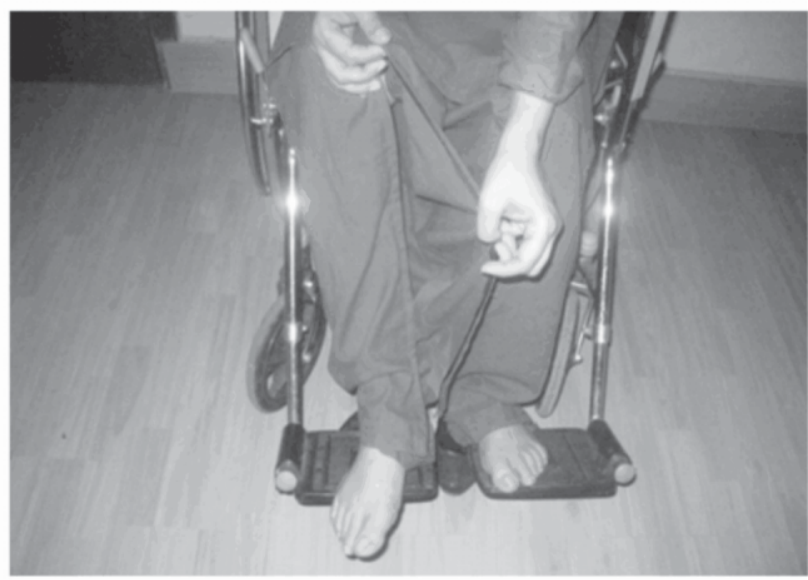

Fig-4. Description of trail adaptive design
The evaluation found a significant positive response from the individuals; all participants found that all categories like comfort and independence in donning and doffing provided through adaptive features of the designed garment which includes shirt with full front opening, easy-to-manage fastenings, style of fastenings, ease of movement and visual appeal was much better than what they had imagined. Thus, the adaptive garment aided the women in reducing many of the problems that they were facing when donning and doffing clothes and increases the comfort and independence of this special group of participants. 


\section{CONCLUSIONS AND RECOMMENDATIONS}

Research Question 1:

Which areas of clothing require adaptation for adult females of Pakistan surfing from Rheumatoid arthritis?

The first question focused on figuring out what the common areas are in the dress that needed to be adapted. Specific physical limitations were common in all the three participants. They were categorized as range of motion, strength, stamina, motor planning, and others. These categories impacted the comfort, independence and self-confidence of this special group while donning and doffing, managing fasteners and also through the style of the clothing. The researcher found the clinical definition of rheumatoid arthritis to be consistent with the identification of the limitations that were earlier categorized, which was supported by ${ }^{21-24}$. Limitations caused by disease usually impact the ability to find suitable clothing. Through observations and in-depth interviews, the researcher found significant problem areas that participants were facing in finding clothes that did not constricting them and would give them the freedom to move and the ease to manage fastenings. The problems with constructing style were solved with designing clothes that had full front open shirt with simple set-in-sleeves, Reglan and Kimono sleeves with moderate neck depth and fairly loose garments. Cottongarments are most suitable compared to woolen, silk and synthetics. Velcro fasteners are highly preferred for quick and fast manipulation

\section{Research Question 2}

How adaptive clothing increases the comfort of adult females with Rheumatoid arthritis?

The researchers uses a co-designing technique to find the change in comfort level of the participants, through creating common clothing features according to the need and preferences of participants in the trail adaptive clothing solution. These features included loose clothing with no define waistline. The adaptive clothing also included a front or side opening, with a simple and basic neckline, and a simple collar. A fastening that was used is Velcro. Shalwar with elasticized waist and elastic band at the bottom of each paincha, zippers on shalwarpaincha and on back of the shirts. All participants found all features very comfortable, they open up that zipper with front open shirt and on shalwarpaincha are very helpful for massage. All these features were seen to also be applicable to those who belonged to other groups with similar range of physical disabilities.

In view of the findings and conclusions of the study, some recommendations are given that could aid further future studies and gives new ideas that could be explored by other researchers in this or in a similar field.

1. Instead of adult female, males with Rheumatoid arthritis should be taken as a sample for future research.

2. Future researchers may increase the sample. More adult females with Rheumatoid arthritis should be included and should be considered for further designs to be made.

3. Wear testing could be done between people with disabilities and normal people. This will allow the researcher to compare differences in the need of their clothing requirements of the participants of varying groups.

\section{Copyright $\odot 22$ July, 2013.}

\section{REFERENCES}

1. Brown, P. J. \&Kundel, C. Clothing Ideas for Mobility Impaired. Lowa: Lowa State University of Science \& Technology. 2001.

2. $\mathrm{Na}, \mathrm{H}$. S. Adaptive clothing designs for the individuals with special needs. Journal of the Korean Society of Clothing and Textiles; 2007.

3. Neelama. Fashion \&Textile Design. Dehli: Sonali Publication; 2009. 
4. Manlow, V. Designing Clothes: Culture and Organization of the Fashion Industry. New Brunswick. USA: Transaction. 2007.

5. Erwin. M. D., Kinchen. L. A., \& Peters. K. A. Clothing for Moderns. New York. Macmillan. 1979.

6. Chang, W. N., Zhao, Y. X., Guo, R. P., Wang, Q., \&Gu, X. $D$. Design and study of clothing structure for people with limb disabilities. Clothing \& Textiles Journal, 2009;2(1), 65-70.

7. Nisbett, D. J. \& Johnson, K. K. P. Clothing fashion ability and students with adisability: Impressions of social and mental competencies. Clothing and Textiles Research Journal. 1992; 11(1), 39-44.

8. Miller, K. Encyclopedia \& Dictionary of Medicine, Nursing \& Allied Health. Saunders an imprint of Elseaver, Inc. 2003.

9. Danish, M. I. Short textbook of medical diagnosis and management. Karachi: Johar Publications. 2010.

10. Guccine, A. A. Arthritis and the Process of Disablement. Boston: Physical Therapy. 1994; Volume 74. No 5 .

11. Valley, P.M., \& Court, J. Reducing the Risk of Musculoskeletal Injury through an Adaptive Clothing and Dressing Program. Occupational Health \& Safety Agency for Healthcare in British. Columbia. 2003.

12. Meinander, H., \&Varheenmaa, M. Clothing and Textiles for Disabled and Elderly People. Vuorimiehentie Fin Land: Julkaisija-Utgivare-Publisher. 2002.

13. Dannecker, E. A, Knoll, V., \& Robinson, M. E. Sex differences in muscle pain: self-carebehaviors and effects on daily activities. The Journal of Pain. . 2008; 9, 200-209.

14. Judi,R. Adaptive Clothing for Mobility Impaired.
Clothing and Textiles Journal. Sagepud.com.2010.

15. Mann,W.C., Kimble.C.et al. Problems with Dressing in the Frail Elderly, American Journal of Occupation Theropy,59,398-408.2005.

16. Gay, L. R., Mills, G. E., \&Airasian, P. Educational Research. (9thed). Upper Saddler River, Nj: Prentice Hall. 2006.

17. Ho, S.M. et al. Garment needs of pregnant women based on content analyses of in-depth interview. Journal of clinical nursing. Hong Kong: Blackwell publishing l.t. 2009.

18. Creswell, J. W. Research design: Qualitative and quantitative approaches. Thousand Oaks, CA: Sage Publications Incorporated. 1994.

19. Bryman, A. Social Research Methods, 3rd edition. Oxford University press. 2008.

20. Null, R. L. \& Cherry, K. F. Universal Design: Creative solutions for A.D.A. compliance. Belmont, CA: Professional Publications, Incorporated. 1996.

21. Yep, J.0. Tools for aiding physically disabled individuals increase independence in dressing. Journal of Rehabilitation. 1977; 39-41.

22. Reich, N. \& Shannon, E. Handicap: Common physical limitation and clothing related needs. Home Economics Research Journal. 1980; 437-444.

23. Newton, A. Taxonomy for independent living used to classify clothing research. Clothing and Textiles Research Journal. 1984-1985; 3(1), 45-47.

24. Elizabeth \& Naomi, Handicap: Common physical limitations and clothing related needs. Journal Home Economics. 1980;8(6): 437-444. 
AUTHOR(S):

1. MRS. NAHEED AZHER

PhD. Student.

Lecturer, Textiles and clothing.

Govt. College of Home Economics,

Gulberg, Lahore. Pakistan.

2. DR. SAMIA KALSOOM

Professor/ Principal

Govt. College of Home Economics,

Gulberg, Lahore. Pakistan.

3. DR. MUHAMMAD SAEED

Associate Professor

Institute of Education \& Research,

University of Punjab, Lahore, Pakistan.

\section{Correspondence Address:}

Mrs. Naheed Azher

Govt. College of Home Economics,

Gulberg, Lahore. Pakistan.

naheed_63@hotmail.com
Article received on: $\quad$ 08/01/2013 Accepted for Publication: 22/07/2013 Received after proof reading: 03/12/2013

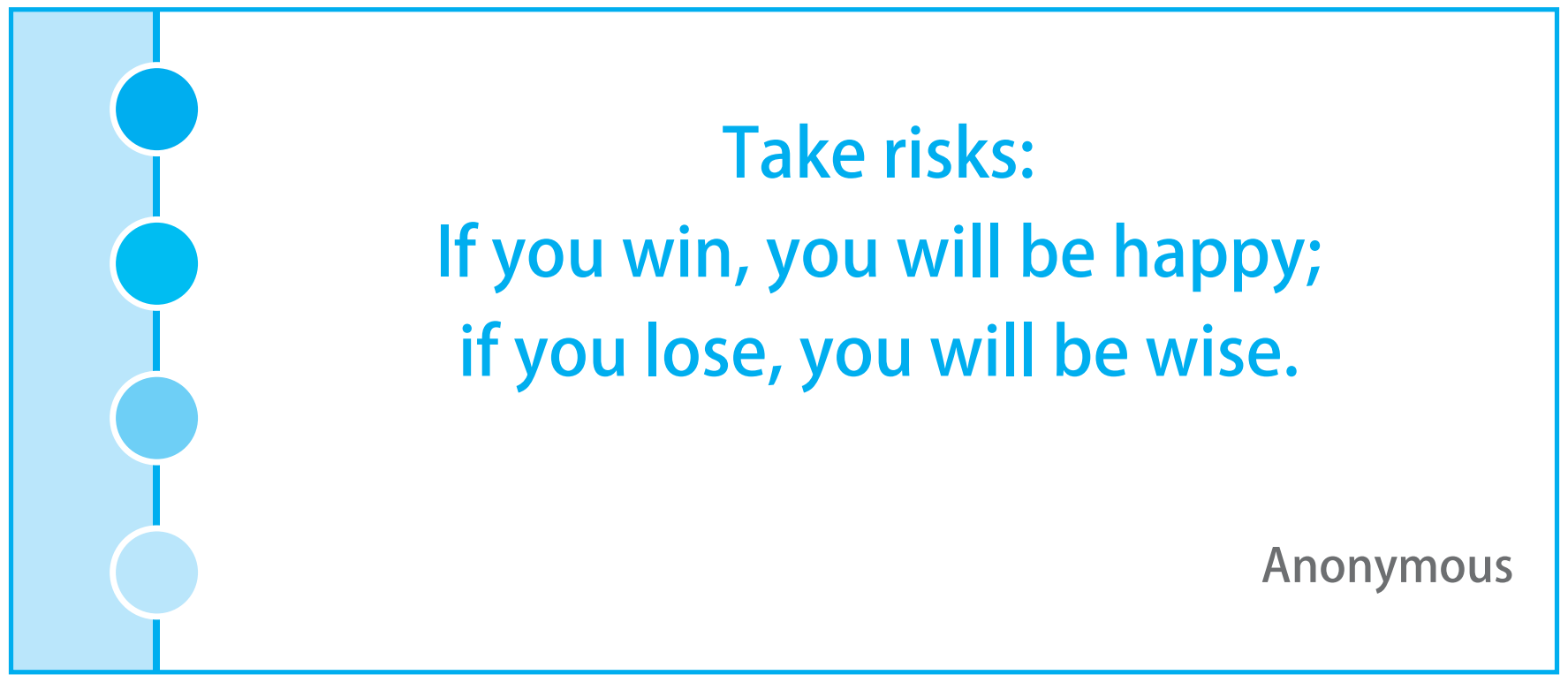

